\title{
Evaluation of the Ecological and Financial Aspects of the Natural Gas Logistics
}

\author{
Igbal A. Guliev \\ Moscow State Institute of International Relations (MGIMO- \\ University) of the Ministry of Foreign Affairs of the \\ Russian Federation \\ Moscow, Russia \\ Elnur T. Mekhdiev \\ Financial University under the Government of the Russian \\ Federation \\ Moscow, Russia
}

\author{
Ekaterina A. Konovalova \\ Bashkir State University \\ Ufa, Russia
}

Alexander V. Bondarenko

Ufa State Petroleum Technological University

Ufa, Russia

\begin{abstract}
The paper presents the results of the analysis of compressed natural gas marine transportation based on ecological and economic criteria, the most economical and ecologically friendly ways of natural gas transportation that are needed to take reasonable managerial decisions as well as to extend use of natural gas as clean fuel.
\end{abstract}

Keywords-compressed natural gas; liquefied natural gas; marine transportation; ecological evaluation; economic evaluation

\section{INTRODUCTION}

Natural gas is used in all power industries and branches of industry. It is obvious that gas is not produced at areas of its consumption. Three ways for gas transportation are competing marine pipeline (MP); liquefied natural gas (LNG) (cryogenic liquid, stripped gas cooled to its transition to liquid condition at atmospheric pressure: at that, gas volume decreases by approximately 600 times; liquefaction temperature is minus $162^{\circ} \mathrm{C}$; a decrease in $\mathrm{LNG}$ volume makes its storage and transportation more convenient; the first LNG tanker built 1959), and; compressed natural gas (CNG) (high-pressure gas that can be transported by special vessels; CNG is compressed to $20-25 \mathrm{MPa}$, which results in a 200-250-fold volume decrease first CNG tanker built in 1960s, first economically viable transportation 2016)

This competition has two interdependent evaluations: economic and ecological. There was no complex economic and ecological evaluation so far, which provides a rationale for the analysis.

Ensuring stable natural gas supplies to consumers is one of the most topical economic and political issues. At that, energy security and gas supply safety should not result in deterioration of environment. Different ways of gas supply (LNG by offshore and onshore gas pipelines) have different specific environmental impact indicators. New ways of gas marine transportation, such as $\mathrm{CNG}$, are developed in addition to the existing ones.

The CNG technology is a new breakthrough technology of marine transportation of natural gas in compressed condition in cylinders on special - CNG carrier - vessels. There is no need in extensive gas treatment before loading the $\mathrm{CNG}$ carrier vessel, which enables direct loading from the field due to use of reservoir gas pressure (gravity loading). Thus, CNG carrier vessels can be used for hard-to-reach, unequipped fields.

One of the prerequisites for implementing the project on CNG transportation by carrier vessels directly from offshore fields is the availability of mature technologies of deep subsea tieback. Another prerequisite is the wide use in the world practice of technology for loading vessels with raw hydrocarbons from offshore terminals without berthing.

\section{LITERATURE REVIEW}

A lot of domestic and foreign scientists devoted their works to the analysis of different ways of $\mathrm{CNG}$ transportation. Attention has been paid to the stage-by-stage development of the CNG market [1], both the principle possibility [2] and various technologies [3] of the sea transportation of CNG have been considered. An analysis of various methods is given by Vasserman and Lavrenchenko [13]. The feasibility of creating ships for transporting gas in a compressed state has been studied by Vlasev [14]. The current state and prospects for CNG transportation are considered in many aspects by Votintsev [15], an assessment of CNG transportation's applicability is given by Novikov, Glagolev and Udalov [8]. An overview of the existing methods of CNG transportation is given by Ryun and Zelenovskaya [9]. Savytskii M., Savytskii A. and Suprunenko [10] considered specific issues of improving the technology of CNG transportation. In Italy, this issue was discussed by Eni back in 2007 - that is more than 10 years ago [5]. It was considered by Kryzhanivskyj and Zaytsev [6] at the 5th International Symposium on Hydrocarbons 
(ISHC-5), by Marongiu-Porcu, Wang and Economides [7] at the Gas Congress in Moscow, by Shakeri and Barati [11] at the 3rd Iran Gas Forum, and by Britton and Dunlop [4] at the Technology Conference in Houston, USA. And the discussion of the issue is continued, according to [12].

Nowadays, all large oil and gas companies face the problem of choice of ways and routes for transporting their product to the consumers. Moreover, different transportation ways have their own strengths and weaknesses, the ratio of which depends on plenty of factors, such as geological, geographical, political, as well as on hydrocarbons use by the consumers. Namely, the scope of natural gas use has been greatly extended for the last years that also resulted in the growth of its transportation ways.

While optimizing logistical systems, companies evaluate and compare product transportation costs by different ways. In order to compare gas transportation ways taking into account transformation/substitution forms, all volume indices are to be reduced to a common denominator - equivalent volume in cubic meters of gas. As a rule, minimum discounted unit costs are used as a criterion at comparing the efficiency of gas transportation ways accounting for possible forms of gas transformation.

These days, competition is, first of all, an economic category. But political and ecological aspects have gained in importance recently shifting the issues towards complex evaluation of both economic and ecological factors, which form the basis for social problems and political solutions. The construction of gas pipelines, terminals, thermal, hydroelectric and atomic power plants causes social and ecological problems. That's why it is needed to evaluate ecological and economic aspects in complex.

Economic task of the research: to determine the economic preferences of $\mathrm{CNG}$ marine transportation for different volumes and distances. Results: the zone of economically sound use of CNG carrier vessels.

Ecological task of the research: to determine the ecological preferences of $\mathrm{CNG}$ marine transportation for different volumes and distances. Results: the zone of ecologically preferable use of CNG carrier vessels.

Ecological and economic task of the research: feasibility study of CNG marine transportation. Results: the zone of ecologically and economically sound use of CNG carrier vessels.

\section{METHODOLOGY}

\section{A. Economic analysis}

The following technologies were used for comparison:

- marine pipeline (MP);

- marine transportation of $\mathrm{LNG}$;

- marine transportation of CNG.

While comparing different transportation ways, one should allow for capital and operating costs for each variant. These costs determine transport tariffs. In general, a transport tariff for each variant is not a constant and depends on transport project implementation terms. Freight traffic and distance (transportation volume and range) are the key parameters that determine transport costs. That is, with different values of the above-mentioned parameters, different transportation ways can be more effective due to a lower tariff. Thus, the final conclusion on the economic efficiency of any transportation way can be made with regard to particular terms of project implementation only.

The tariff of one transportation way can be the lowest within the whole scope of freight traffics and distances under consideration. Or the leaders can change under some circumstances, and another transportation way can be the most economical. The second variant is possible, when compared transport technologies have different cost structures.

The tariff is influenced by project capital and operating costs to the greatest extent, whereas the value of transport total unit cost $(\sigma)$ is defined as:

$$
\sigma=\frac{s}{M-L}
$$

Where: $\mathrm{S}$ is the aggregate (capital and operating inclusive) cost of cargo carriage by the mode of transport (expressed in particular currency), which depends on both freight traffic and distance; $\mathrm{M}$ is the yearly freight traffic (tones); $\mathrm{L}$ is the transportation distance $(\mathrm{km})$.

In general terms, the value of $\mathrm{S}$ may be expressed as:

$$
S=S_{1}+S_{2}+S_{7}+S_{4}
$$

Where: $S_{1}$ is costs that depend on neither freight traffic $M$ nor the distance $\mathrm{L}$ (for example, costs for $\mathrm{R} \& \mathrm{D}$ and design works); $S_{2}$ is costs that depend on the freight traffic $M$ (for example, project transport purchase and maintenance costs); $\mathrm{S}_{3}$ is costs that depend both on the freight traffic $M$ and the distance L (for example, costs for fuel and energy resources); $\mathrm{S}_{4}$ is costs that depend on the distance $\mathrm{L}$ (for example, costs for road building, pipe laying, etc.).

The transport tariff (unit of currency per thousand $\mathrm{m} 3$ per $100 \mathrm{~km}$ ) is the key criterion to compare technologies, while specific capital investments are auxiliary. All calculations are done in actual prices (unadjusted for inflation). The accounting period is 25 years. The reporting year is 2016. The transport tariff calculation criterion is the IRR of commercial efficiency $12 \%$. The discount rate is $10 \%$.

The primary result of the work performed is the definition of dependency (and graphic representation) of key and auxiliary criteria on transport volume and distance for all the technologies studied.

Each transportation variant is considered as an independent investment project, whereby cash flows, including operating and investment activity inflows and outflows, are modeled.

Transport technologies are compared as follows:

- Development of basic data for calculations.

- Cash flow modeling for each way of natural gas transportation. 
- Calculation of multiple tariffs depending on transport volume and distance.

- Construction of tariff - freight traffic and distance charts, and identification of their crossing points for different transport technologies.

- Identification of effective application areas for each transport technology (matrix of effectiveness).

The basic data to model cash flows were developed on the first stage. They include:

- evaluation of capital costs for each way of natural gas transportation;

- evaluation of operating costs for each way of natural gas transportation;

- evaluation of investment projects differing in transportation ways;

- evaluation of investment projects unitary for all transportation ways.

\section{B. Ecological analysis}

Environmental impact, first of all, involves atmospheric emissions. Unlike solid fuel, gas-related emissions are insufficient.

At present, one of the most complex parameters of ecological compatibility is carbon footprint. The international carbon footprint evaluation method involves evaluation of greenhouse gases emission from the specific energy carrier for the whole life cycle of a specific technology. As for the LNG technology, carbon footprint is to be evaluated by calculating greenhouse gas emissions at the following stages:

- $\quad$ gas recovery at the field;

- pipeline transportation to the LNG plant;

- $\quad$ LNG production at the plant;

- $\quad$ loading to gas carrier vessels;

- $\quad$ LNG marine transportation;

- LNG unloading;

- $\quad$ regasification at the terminal;

- gas pipeline transportation to the consumers

- gas burning by the consumers.

The main ecological aspect at transporting natural gas by marine pipelines is emissions from gas-compressor units (GCU) of compressor stations that compress natural gas to supply it to the marine gas pipeline. New generation GCU with lowemission combustion chambers have become the priority in order to reduce atmospheric emissions.

The gas pipeline at the bottom of the sea should not adversely affect the marine environment. Gas pipelines are examined on schedule to find and assess deformations, seafloor scours, welding defects, buckles, pipeline protection damages and gas leaks, preventing gas pipeline malfunction or accidents
Fluctuations of operating parameters, pressure, and temperature are continuously controlled. Higher demands of industrial and ecological safety are set to gas pipelines operated in the aggressive hydrosulfuric environment (the Black Sea projects).

While transporting LNG by LNG carrier vessels, first of all, NOx and $\mathrm{CO}$ emissions are to be referred to ecological aspects. The bulk of atmospheric emissions are accounted for by power and heat production needed for technological processes at LNG plants, regasification plants, and LNG receiving terminals. Emissions result from operation of compressors, pumps and piston engines, as well as flare units.

Aiming at emissions minimization, each LNG project provides for choice of technological equipment (for example, evaporators for regasification terminals that differ greatly in operating characteristics and environmental adverse impact) and electricity and heat sources (for example, use of energy from third companies).

The most important ecological aspect characteristic to $\mathrm{CNG}$ transportation by $\mathrm{CNG}$ carrier vessels is atmospheric emissions at:

- Compressing natural gas at coastal boosting compressor stations (BCSs) at gas loading and unloading points;

- Transportation of natural gas by carrier vessels and operation of service vessels.

At BCSs, emissions are mainly formed at fuel gas combustion in GCU.

When loading gas to CNG carrier vessels from gas wells of offshore fields, one should consider negative environmental impact that can be expected from subsea production systems (for example, X-tree, service lines and gas and water injection devices).

While operating gas carrier vessels, alongside with fuel combustion in vessel engines, pollutants can be emitted to atmosphere from blow-down masts (one or several) equipped with flaring system. The mast is needed to control emissions of high-pressure gases (from freight containers) and low-pressure gases (from hold spaces) and to ensure popping of gas or gas combustion products.

\section{DISCUSSION}

\section{A. Economic Analysis}

Analytics (theoretical calculations) is performed for transportation volumes and distances with the purpose of defining the preferable zones for different technologies. The calculation results are presented in a graphic form. There are zones with absolute preferences for the only technology and zones with preferences for several technologies.

The key criterion to compare technologies is a transport tariff; Table 1 and Fig. 1 show gas transport tariffs by technologies (distance - 1,000 km). 
TABLE I. TRANSPORT TARIFF (EURO / 1000 M3 / 100 KM)

\begin{tabular}{|c|l|l|l|l|l|l|}
\hline \multicolumn{2}{|c|}{$\begin{array}{c}\text { Transportation } \\
\text { technology }\end{array}$} & \multicolumn{5}{|c|}{ Transportation volume, bln m3/yr } \\
\cline { 2 - 7 } & 1.44 & 4.31 & 7.18 & 10.78 & 14.37 & 21.55 \\
\hline $\begin{array}{l}\text { Gas marine pipeline } \\
\text { transportation }\end{array}$ & 50.2 & 19.0 & 12.7 & 9.0 & 7.3 & 5.6 \\
\hline $\begin{array}{l}\text { Liquefied gas marine } \\
\text { transportation }\end{array}$ & 22.8 & 19.1 & 15.6 & 14.2 & 13.1 & 12.2 \\
\hline $\begin{array}{l}\text { Compressed gas marine } \\
\text { transportation }\end{array}$ & 20.8 & 16.1 & 12.2 & 10.5 & 10.3 & 9.7 \\
\hline
\end{tabular}

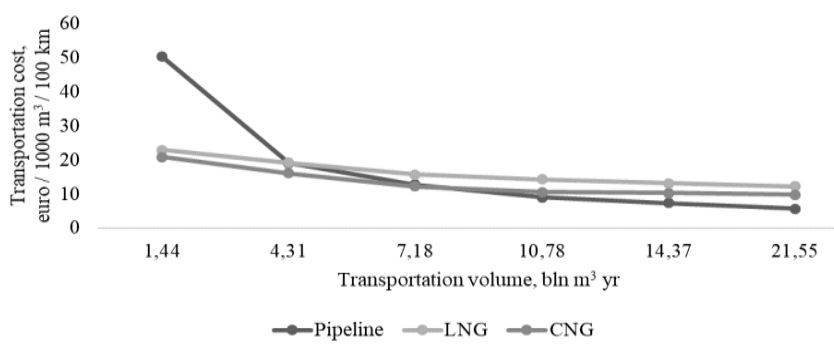

Source: [7], [1]

Fig. 1. Gas transport tariffs by technologies.

The same data were produced for distances $300 \mathrm{~km}, 2,000$ $\mathrm{km}, 4,000 \mathrm{~km}$, and $5,000 \mathrm{~km}$. As a result, the matrix of technology effectiveness (Table 2) is developed, and the areas of effective application of gas transportation technologies are defined.

TABLE II. MATRIX OF TECHNOLOGY EFFECTIVENESS

\begin{tabular}{|l|l|l|l|l|l|l|}
\hline \multirow{2}{*}{$\begin{array}{c}\text { Distance, } \\
\mathbf{k m}\end{array}$} & \multicolumn{6}{|c|}{ Transportation volume, bln m3/yr } \\
\cline { 2 - 7 } & 1.44 & 4.31 & 7.18 & 10.78 & 14.37 & 21.55 \\
\hline 300 & $\mathrm{CNG}$ & $\mathrm{MP}$ & $\mathrm{MP}$ & $\mathrm{MP}$ & $\mathrm{MP}$ & $\mathrm{MP}$ \\
\hline 1,000 & $\mathrm{CNG}$ & $\mathrm{CNG}$ & $\mathrm{CNG}$ & $\mathrm{MP}$ & $\mathrm{MP}$ & $\mathrm{MP}$ \\
\hline 2,000 & $\mathrm{LNG}$ & $\mathrm{CNG}$ & $\mathrm{CNG}$ & $\mathrm{CNG}$ & $\mathrm{CNG}$ & $\mathrm{MP}$ \\
\hline 3,000 & LNG & $\mathrm{CNG}$ & $\mathrm{CNG}$ & $\mathrm{CNG}$ & $\mathrm{LNG}$ & LNG \\
\hline 4,000 & LNG & LNG & LNG & LNG & LNG & LNG \\
\hline 5,000 & LNG & LNG & LNG & LNG & LNG & LNG \\
\hline
\end{tabular}

Note: MP - marine pipeline transportation; $\mathrm{CNG}$ - compressed natural gas marine transportation; LNG liquefied natural gas marine transportation.

Source: [4], [1]

1) Choice of a natural gas marine transportation way evidence from potential projects

The paper covers calculations for projects implemented in the Black and Baltic Seas. At that, we studied gas transportation volumes equal to 3 bln $\mathrm{m} 3 / \mathrm{yr}$ and 5 bln m3/yr. When supplying gas through the area of the Black Sea, compressor station Russkaya can be considered as a start point. The destination points are Bulgaria and Turkey. When supplying gas through the area of the Baltic Sea, compressor stations Portovaya or Slavyanskaya can be considered as start points. The destination points are Kaliningrad, Germany and Great Britain.

On the diagram that illustrates the choice of a preferable gas transportation technology depending on the transport volume and distance for all the technologies studied, we plotted points corresponding to projects presented in this section. Fig. 2 shows the configuration of the preferable transport technology areas underlining gas transportation volumes and distances studied.

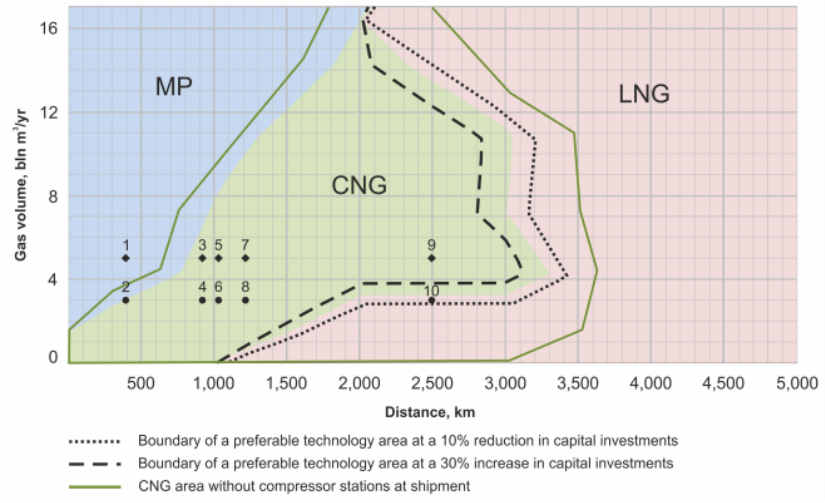

Note: Gas volume: -3 bln m3/yr; -5 bln m3/yr. Route: 1, 2 - compressor station Russkaya Turkey, $389 \mathrm{~km} ; 3,4$ - compressor station Russkaya - Bulgaria, $927.2 \mathrm{~km} ; 5,6$ - compressor station Portovaya - Kaliningrad, 1,040.5 km; 7, 8 - compressor station Portovaya - Germany, 1,225.5 km; 9, 10 - compressor station Portovaya - Great Britain, 2,500 km. Source: [11], [8], [2].

Fig. 2. Configuration of areas of gas transportation technologies' effective application.

According to Fig. 2, when transporting 3 bln m3/yr for 300 to approximately $1,500 \mathrm{~km}$ (we have studied the distances of $389 \mathrm{~km}, 927.2 \mathrm{~km}, 1,040.5 \mathrm{~km}, 1,225.5 \mathrm{~km})$, the most effective is the CNG technology. When transporting 3 bln $\mathrm{m} 3 / \mathrm{yr}$ for $2,500 \mathrm{~km}$, the $\mathrm{CNG}$ and LNG technologies can have the same efficiency.

When transporting $5 \mathrm{bln} \mathrm{m3/yr} \mathrm{for} \mathrm{approximately} 1,000 \mathrm{~km}$ and more (we have studied distances $927.2 \mathrm{~km}, 1,040.5 \mathrm{~km}$, $1,225.5 \mathrm{~km}$ and $2,500 \mathrm{~km}$ ), the most effective is the CNG technology. When transporting 5 bln $\mathrm{m} 3 / \mathrm{yr}$ for $389 \mathrm{~km}$, the marine pipeline transportation technology is the most efficient.

Also, in Fig. 2, the green line shows the extension of the area of effective application of the CNG technology, if there is no need in building special onshore compressor stations. It is possible, when existing facilities can be employed. This variant provides for effective application of the CNG transportation technology in relatively small volumes (up to 3 bln m3/yr) for relatively large distances (up to $3,000 \mathrm{~km}$ and more).

\section{B. Ecological analysis}

The authors have conducted the comparative analysis of air pollution with nitrogen oxides (NOx) and carbon oxide (CO) taking into account the three above-mentioned marine transportation ways by gas transport directions:

- The Black Sea route $-400 \mathrm{~km}$ from compressor station Beregovaya; it is considered as a prototype of the Turkish Stream $900 \mathrm{~km}$ from compressor station Russkaya;

- The Baltic Sea route - from compressor station Portovaya with three unloading variants - Kaliningrad 
Region, Germany and Great Britain, with transportation distances $900 \mathrm{~km}, 1,200$ and 2,500 km, respectively.

The following gas transportation volumes by these routes are studied: 3.0 and 5.0 bln m3/yr. By the Black Sea route, 16 bln $\mathrm{m} 3 / \mathrm{yr}$ of gas are transported for $400 \mathrm{~km}$.

Variants of gas supply with increasing volumes for $900 \mathrm{~km}$ are studied by the following transport and process chains:

- Gas transportation by marine pipelines (at the bottom of the sea) using the onshore infrastructure - gas is supplied from compressor station Beregovaya or compressor station Russkaya;

- $\quad$ CNG transportation by gas carrier vessels by the Black Sea route. Gas is supplied from the gas treatment infrastructure, via BCSs and using the load terminals (anchor buoys or road loading inclusive).

The analysis showed that different gas supply ways, using marine pipelines, CNG or LNG carrier vessels, have different carbon footprints. And their comparative evaluation for specific gas marine transportation projects in the areas of the Black and Baltic Sea makes it possible to conclude that the new CNG transport technology reduces carbon footprint of the natural gas marine transportation. The CNG technology in ongoing projects of the Baltic Sea is characterized by a smaller carbon footprint as compared to marine pipeline transportation of gas in the following volumes:

- up to 10-12 bln m3 for the distance of up to $1,000 \mathrm{~km}$;

- 12 to 20 bln $\mathrm{m} 3$ for the distance of 1,000 to $2,000 \mathrm{~km}$;

- 20 to $25 \mathrm{bln} \mathrm{m} 3$ for the distance of 2,000 to $2,500 \mathrm{~km}$.

Transportation of natural gas in volumes exceeding 12-15 bln $\mathrm{m} 3$ for $1,000 \mathrm{~km}, 15-20$ bln $\mathrm{m} 3$ for 1,000 to $2,000 \mathrm{~km}$ and $20-25$ bln $\mathrm{m} 3$ for 2,000 to $2,500 \mathrm{~km}$ by marine pipelines is characterized by a smaller carbon footprint, if compared to the CNG technology.

Specific emissions by different variants are presented in Fig. 3 and 4

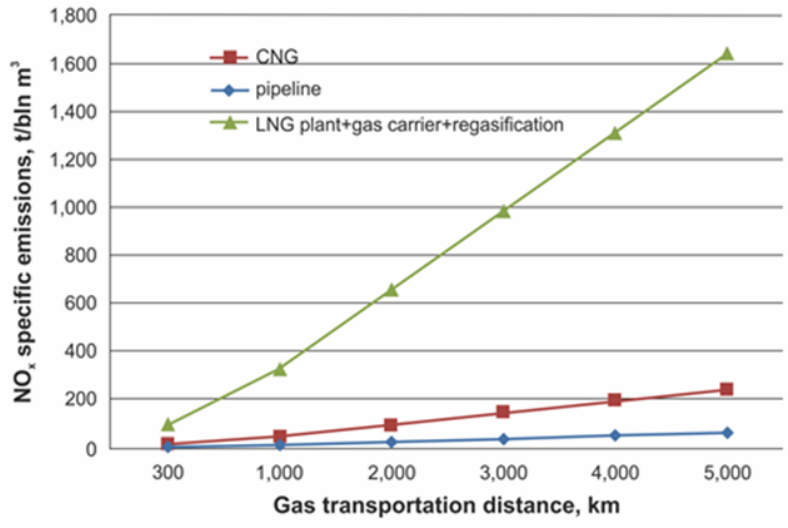

Source: [9].

Fig. 3. $\mathrm{NO}_{\mathrm{x}}$ emissions depending on transportation distance.
Source: [9].

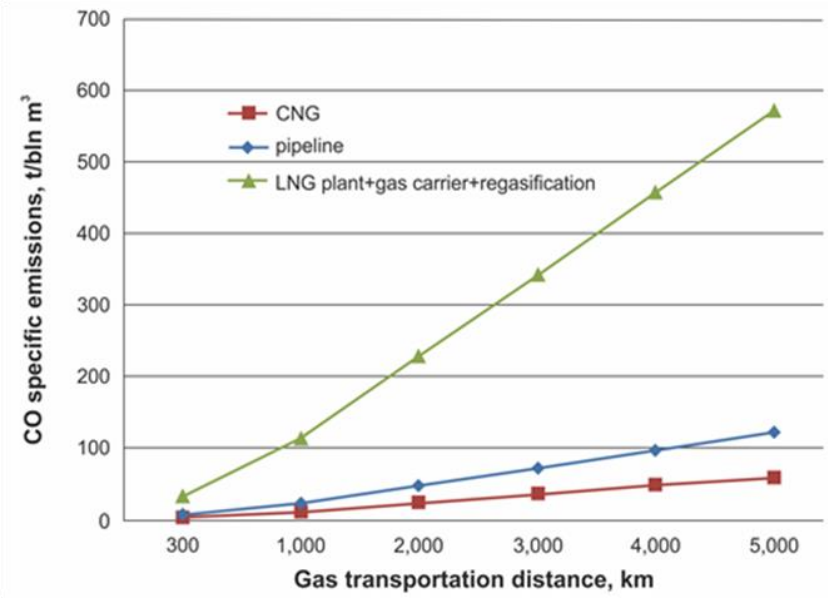

Fig. 4. $\mathrm{CO}$ emissions depending on transportation distance.

Finally, the authors have identified the areas of effective application of different technologies with regard to ecological factors (Fig. 5).

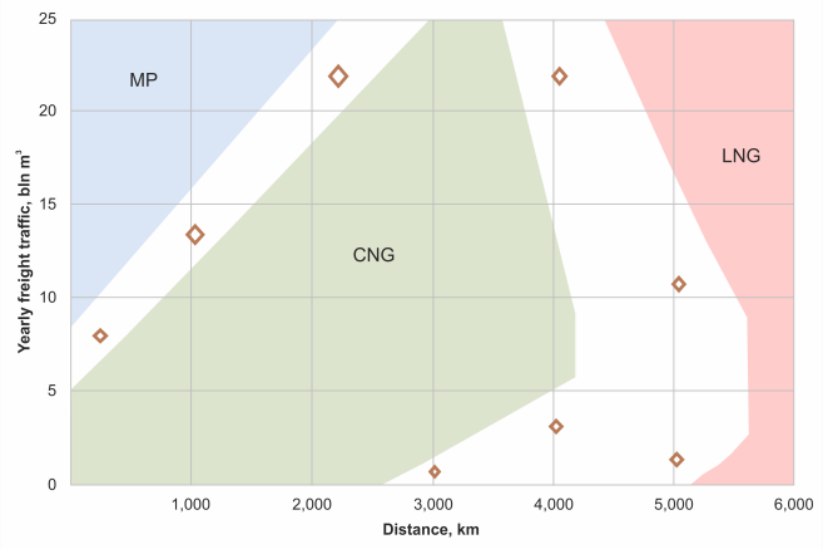

Source: [11], [8], [2]

Fig. 5. Areas of effective application of different gas transportation technologies with minimum impact on the atmosphere.

\section{CONCLUSION}

The comparative analysis of the economic efficiency of different gas marine transportation ways showed that the $\mathrm{CNG}$ technology, on the one hand, can promote the diversification of products and services of a modern oil and gas company and, on the other hand, can reduce costs for gas transportation to the consumers. In particular, if the existing gas transportation infrastructure is used, the implementation of the compressed gas transportation technology in the areas of the Black and Baltic Sea will result in deep cut of logistical costs at transportation of up to $3 \mathrm{bln} \mathrm{m} 3$ of gas per year. When transporting 3 to 5 bln $\mathrm{m} 3$ by the Black Sea routes, a deeper substantiation of the economic efficiency of transportation ways is needed to choose the right one. 
The CNG transportation efficiency is achieved due to systematic use of advantages of transporting gas in this way, namely:

- Lower cost of onshore facilities as compared to the LNG technology, where complex expensive liquation, storage and regasification systems are needed;

- Environmental safety, which is achieved not least because of low gas losses during transportation.

Use of marine gas pipelines is characterized by smaller carbon footprint versus the CNG technology, when transporting gas to long distances (at transportation volume increase). But one should take into account that marine pipelines have limitations in length and depth.

If natural gas is transported for more than $4,000 \mathrm{~km}$, the CNG technology is less preferable than the LNG one, because carbon footprint grows with an increase in distance at transporting gas by $\mathrm{CNG}$ carrier vessels (at transportation volume increase). But it should be noted that LNG transportation systems need large volumes of gas transported and sufficient costs for onshore infrastructure.

Thus, in prospective projects in the areas of the Baltic and Black Sea, the use of the CNG technology to transport gas in volumes of 3 and $5 \mathrm{bln} \mathrm{m} 3 / \mathrm{yr}$ for 400 to $2,500 \mathrm{~km}$ is the most environmentally friendly way, if compared to marine pipelines and LNG carrier vessels.

\section{REFERENCES}

[1] A. A. Battalkhanov, "Phased development of the market of CNG," Mezhdunarodnyi nauchnyi zhurnal [International Scientific Journal], no. 6 , pp. 4-11, 2015.

[2] A. N. Blinkov and A. A. Vlasov, "Offshore compressed natural gas transportation," Morskaya Birzha [Maritime Market magazine], no. 2 (16), pp. 65-69, 2006

[3] A. N. Blinkov, A. A. Vlasov, A. V. Litsis and V. K. Shurpyak, "CNG a New offshore gas transportation technology: State of the art, prospects, problems," Nauchno-tekhnicheskii sbornik Rossiiskogo morskogo registra sudokhodstva [Research Bulletin by Russian Maritime Register of Shipping], no. 30, pp. 127-162, 2007.

[4] P. S. Britton and J. P. Dunlop, "CNG and other LNG alternatives - CNG marine gas transport solution: Tested and ready," in Offshore Technology Conference. Houston, Texas, U.S.A, 2007, pp. 1-7.

[5] Eni, Encyclopaedia of Hydrocarbons. Roma: Istituto della Enciclopedia italiana Fondata da giovanni treccani, 2007.

[6] Je. I. Kryzhanivskyj and V. V. Zaytsev, "The concept of fast alternative delivery of natural gas to Ukraine," in The 5th International Symposium on Hydrocarbons \& Chemistry (ISHC5). Marine CNG Transportation, Platts Caribbean Energy Conference, Algiers, 2013, p. 127.

[7] M. Marongiu-Porcu, X. Wang and M. J. Economides, "The economics of compressed natural gas sea transport," in SPE Russian Oil \& Gas Conference and Exhibition, Moscow, Russia, 28-30 October 2008. Moscow: Society of Petroleum Engineers, 2008, pp. 1-12.

[8] A. I. Novikov, A. I. Glagolev and D. A. Udalov, Marine transportation of compressed natural gas. State of the Art and Prospects. Moscow: OOO Gazprom expo, 2010.

[9] Ch. K. Ryun and E. V. Zelenovskaya, "Review of the existing technologies of the long-distance gas transportation and assessment of their applicability," Neft, Gaz i Biznes [Oil, Gas and Business], no. 3, pp 3-9, 2011.

[10] M. M. Savytskii, O. M. Savytskii and V. O. Suprunenko, "Determination of internal circuit keels parameters of flexible skirt of amphibious hovercraft vessel," Visnik NUK. Elektronne vidannya [NUS Journal. Electronic Edition], no. 1, pp. 4-14, 2013.

[11] O. Shakeri and A. Barati, "Marine transportation of compressed natural gas," in The 3rd Iran Gas Forum, September 26-27. Iran: Iranian Fuel Conversation Organization (IFCO), 2009.

[12] Trans Ocean Gas CNG Compressed Natural Gas Transportation by Ship 2013. Retrieved from: www.transcanada.com.

[13] A. A. Vasserman and G. K. Lavrenchenko, "Analysis of methods of gases maritime transportation," Tekhnicheskie gazy [Journal Industrial Gases], no. 2, pp. 57-65, 2014.

[14] M. V. Vlasev, Feasibility study of practicability to construct liquefied natural gas carrier vessels. Ph.D. Thesis Abstract. St. Petersburg, 2015.

[15] A. V. Votintsev, "Compressed natural gas transportation," Gazovaya promyshlennost [Gas Industry], no. 2, pp. 62-63, 2007. 